\title{
pesquisa
}

NASCIMENTO, A.R.P.; MARIANO, R.L.R.; SILVA, E.I. Hospedeiros alternativos de Acidovorax avenae subsp. citrulli. Horticultura Brasileira, Brasília, v.22, n.3, p.345-349, ,jul-set 2004..

\section{Hospedeiros alternativos de Acidovorax avenae subsp. citrulli}

\author{
Ana Rosa P. Nascimento ${ }^{1,2 *}$; Rosa L.R. Mariano ${ }^{2 * *}$; Elias I. Silva ${ }^{2}$ \\ ${ }^{1}$ UNEB/DTCS, 48900-000 Juazeiro-BA; ${ }^{2}$ UFRPE/DEPA/Fitossanidade, 52171-900 Recife-PE; "Bolsista PICDT-CAPES; " ${ }^{\text {*t }}$ Bolsista \\ CNPq; E-mail: anarpeixoto@uol.com.br
}

\section{RESUMO}

Uma das principais doenças que afeta o meloeiro é a manchaaquosa, causada pela bactéria Acidovorax avenae subsp. citrulli (Aac). Visando conhecer hospedeiros alternativos de Aac, plantas no estágio de primeiras folhas definitivas, de várias espécies/cultivares, incluindo cucurbitáceas, solanáceas, gramíneas, leguminosas e caricáceas, foram inoculadas pela atomização da parte aérea com suspensão dos isolados Aac 1.49 e Aac 12.13, oriundos de melão e melancia, respectivamente. A suscetibilidade das plantas aos isolados foi avaliada pelo período de incubação (PI) e incidência da doença (INC). Caupi, feijão, fumo e milho não apresentaram sintomas. Os menores PIs foram observados em cucurbitáceas ( $3,0 \mathrm{~d})$, com exceção da bucha $(6,83$ d). Incidências da doença acima de $90 \%$ foram observadas em cucurbitáceas, excetuando a bucha e em solanáceas, para ambos os isolados de Aac. Em outro experimento, frutos de abóbora, abobrinha, berinjela, mamão, maxixe, melancia, melão, pepino, pimentão e tomate foram analisados quanto à suscetibilidade aos isolados Aac 1.49 e Aac 12.13. Os frutos foram inoculados pelo método de injeção subepidérmica, determinando-se PI, INC e severidade, avaliada pelo diâmetro da lesão externa (DLE) e profundidade da lesão (PL). Menores PIs (2,0 d) foram detectados em frutos de mamão, melancia, melão e pimentão. Incidência de 100\% foi observada em todos os frutos inoculados, com exceção da abobrinha $(93,75 \%)$ e da abóbora $(34,37 \%)$. Maiores DLEs foram observados em pepino $(1,47 \mathrm{~cm})$ para o isolado Aac 1.49 e em melancia $(1,60 \mathrm{~cm})$ e melão $(1,07 \mathrm{~cm})$ para Aac 12.13 . As maiores PL foram constatadas em melancia $(1,72$ e $0,75 \mathrm{~cm})$ respectivamente para Aac 1.49 e Aac 12.13. Frutos de berinjela não apresentaram sintomas externos embora as lesões internas tenham sido profundas.

\begin{abstract}
Alternative hosts of Acidovorax avenae subsp. citrulli

One of the most important melon diseases is the bacterial blotch caused by Acidovorax avenae subsp. citrulli (Aac). Alternative hosts of this bacterium were determined in plants at the first true leaf stage of several species/cultivars, including cucurbits, solanaceous, gramineous, leguminous and caricaceous species. They were inoculated by spraying foliage with bacterial suspensions of strains Aac 1.49 and Aac 12.13, isolated from melon and watermelon, respectively. The susceptibility of plants was evaluated based on the incubation period (PI) and disease incidence (INC). Cowpea, bean, tobacco and maize did not show symptoms. The lowest PIs were observed in cucurbits ( $3.0 \mathrm{~d})$, except sponge gourd (6.83 d). Disease incidences higher than $90 \%$ were observed in cucurbits, except sponge gourd, and in solanaceous species for both Aac strains. In another experiment, fruits of pumpkin, squash, eggplant, papaya, bur gourd, watermelon, melon, cucumber, bell pepper and tomato were analyzed for susceptibility to strains Aac 1.49 and Aac 12.13. Fruits were inoculated by sub-epidermal injection. PI and INC were determined and disease severity was evaluated by measuring external lesion diameter (DLE) and lesion depth (PL). Lowest PIs (2.0 d) were detected in fruits of papaya, watermelon, melon and bell pepper. One hundred percent incidence was observed in all inoculated fruits excepting squash $(93.75 \%)$ and pumpkin $(34.37 \%)$. Highest DLEs were seen in cucumber $(1.47 \mathrm{~cm})$ for strain Aac 1.49, and by watermelon $(1.60 \mathrm{~cm})$ and melon $(1.70 \mathrm{~cm})$ for Aac 12.13 . Highest PLs were presented by watermelon $(1.72$ and $0.75 \mathrm{~cm}$ respectively for strains Aac 1.49 and Aac 12.13). Eggplant fruits did not show external symptoms but internal lesions were deep.
\end{abstract}

Keywords: Cucumis melo, bacterial wilt blotch, bacterium.

Palavras-chave: Cucumis melo, mancha-aquosa, bactéria.

\section{(Recebido para publicação em 11 de setembro de 2003 e aceito em 14 de abril de 2004)}

A cultura do meloeiro (Cucumis melo L.) tem grande importância econômica para o Nordeste do Brasil, responsável por aproximadamente $93 \%$ da produção nacional. Destacam-se como principais produtores os estados do RN, BA, CE, PE e PB (IBGE, 2001). Um dos principais patógenos que afeta o meloeiro é a bactéria Acidovorax avenae subsp. citrulli (Schaad et al.) Willems et al., que causa a mancha-aquosa ou mancha bacteriana do fruto (Santos e Viana, 2000). Esta enfermidade foi primeiramente descrita nos Estados Uni- dos, em melancia (Citrullus lanatus L.) (Webb e Goth, 1965), e posteriormente em melão (Isakeit et al., 1997) e abóbora (Cucurbita maxima Duchesne) (Langston et al., 1999). No Brasil, o patógeno foi relatado causando manchas em frutos de melancia, no estado de SP (Robbs et al., 1991) e em meloeiro nas regiões Nordeste, Sudeste e Centro-Oeste (Robbs et al., 1992).

No RN, a mancha-aquosa foi detectada pela primeira vez em frutos de melão, em 1997 (Assis et al., 1999), reduzindo o valor comercial do melão amarelo, tipo mais plantado na região. Posteriormente, a doença foi observada nos estados do CE (Santos e Viana, 2000), PE (Mariano et al., 2001), MG (Macagnan et al., 2002) e RS (Ueno et al., 2003).

Os sintomas da mancha-aquosa apresentam-se na forma de lesões nas plântulas, folhas, ramos e frutos. Plântulas oriundas de sementes infectadas apresentam inicialmente extensas manchas encharcadas nas folhas cotiledonares, que se tornam verde-escuras e marrons, coalescendo e poden- 
do causar tombamento e morte. Ocasionalmente, ocorre necrose no hipocótilo. Nas folhas de plantas adultas, as manchas são inicialmente pequenas, com aspecto oleoso. Posteriormente tornamse necróticas com ou sem halo e em alguns casos apresentam-se como manchas angulares, estendendo-se até a nervura central das folhas. Os sintomas mais típicos da doença ocorrem nos frutos na forma de pontos oleosos que se expandem e se tornam manchas marrons, com ou sem rachaduras. A lesão se aprofunda na polpa como uma podridão seca, podendo ou não atingir as sementes, que podem ser contaminadas tanto externa quanto internamente (Mariano et al., 2001). Em estádio mais adiantado da doença pode ocorrer o apodrecimento total do fruto, como resultado da ação de microrganismos secundários (Viana et al., 2000).

Com relação à gama de hospedeiros, Acidovorax avenae subsp. citrull (Aac), além de causar mancha-aquosa em melão, melancia e abóbora, foi também detectada em frutos de melão-pepino (Cucumis melo var cantalupensis Naudin) (Oliveira et al., 2003), na invasora Cucumis myriocarpus Naudin subsp. myriocarpus (O’Brien, 2002), em mudas de berinjela (Solanum melongena L.) provenientes de sementes infectadas, e sementes de tomate (Lycopersicon esculentum Mill.) infectadas com o patógeno (Assouline et al., 1997). Segundo Viana et al. (2000), é possível que o patógeno sobreviva em cucurbitáceas silvestres, como bucha (Luffa cylindrica L.) e melão de São Caetano (Momordica charantia L.), que são comuns nos solos arenosos do Nordeste.

O objetivo deste trabalho foi testar diferentes espécies/cultivares quanto à suscetibilidade a Aac visando o conhecimento de hospedeiros alternativos deste importante fitopatógeno.

\section{MATERIAL E MÉTODOS}

\section{Obtenção dos isolados de} Acidovorax avenae subsp. citrulli $\mathrm{e}$ preparo de inóculo

Foram utilizados os isolados Aac 1.49 e Aac 12.13 de A. avenae subsp. citrulli. Aac 1.49 foi obtido de fruto de melão com sintomas característicos da mancha-aquosa, coletado em plantio comercial no município de Baraúna, $\mathrm{RN}$, estando preservado na coleção de culturas do Laboratório de Fitobacteriologia da UFRPE. Aac 12.13 foi obtido de fruto de melancia, proveniente do município de Presidente Prudente, em SP, e pertencente à coleção de culturas do Instituto Biológico de São Paulo. Para as inoculações foram utilizadas suspensões bacterianas em água destilada contendo Tween $20(0,05 \%)$ ajustadas à concentração de $3,4 \times 10^{7}$ UFC $\mathrm{ml}^{-1}$, de acordo com equação prédeterminada.

Reação de plântulas de diferentes espécies/cultivares a Acidovorax avenae subsp. citrulli, em condições de casa de vegetação

Várias espécies/cultivares foram testadas: i) Cucurbitáceas: pepino (Cucumis sativus L) cv. SMR 58; melancia, cv. Charleston Gray; maxixe (Cucumis anguria L.) cv. do Norte; cabaça (Lagenaria vulgaris Ser.); bucha; melão de São Caetano; melão cv. Pele de sapo; melão-pepino, abobrinha (Cucurbita pepo L.) cv. Menina brasileira; abóbora (Cucurbita moschata Duchesne) cvs. Menina creme e Baiana tropical, e abóbora moranga (Cucurbita maxima Duchesne) cv. Exposição; ii) Solanáceas: tomate, cv. Santa Clara; berinjela, cv. Comprida roxa; pimentão (Capsicum annum L.) cv. All big; fumo (Nicotiana tabacum L.); iii) Gramíneas: milho (Zea mays L.) cv. São José; iv) Leguminosas: feijão (Phaseolus vulgaris L.) cv. Princesa; feijão caupi (Vigna unguiculata [L.] Walp.; e v) Caricacae: mamão (Carica papaya L.) cv. Sunrise solo. As sementes foram obtidas das empresas Petoseed, Empresa Pernambucana de Pesquisa Agropecuária (IPA, Recife) e Embrapa Semi-Árido, Petrolina (PE).

As plântulas foram obtidas pelo semeio em recipientes plásticos com capacidade de $400 \mathrm{ml}$, contendo solo esterilizado com brometo de metila, acrescido de substrato organo-vegetal Plantmax $^{\hat{a}}$, na proporção de 1:1. As plântulas foram inoculadas quando apresentavam o primeiro par de folhas definitivas, pela atomização da suspensão bacteriana até o escorrimento. Em seguida foram submetidas à câmara úmi- da por $72 \mathrm{~h}$ e a seguir mantidas em condições de casa de vegetação. As avaliações foram realizadas, diariamente, por um período de até 10 dias. Foram estimadas as variáveis período de incubação (PI) e incidência (INC). Plantas que não apresentaram sintomas tiveram PI ajustado para o período de avaliação total acrescido de mais um dia, conforme proposto por Iamsupasit et al. (1993).

O delineamento experimental foi inteiramente casualizado, em arranjo fatorial $2 \times 20$, representado por dois isolados do patógeno e 20 diferentes espécies/cultivares com três repetições, sendo a unidade experimental constituída por três plantas.

Reação de frutos de diferentes espécies a Acidovorax avenae subsp. citrulli, em condições de casa de vegetação

Frutos de abóbora, abobrinha, berinjela, mamão, maxixe, melancia, melão, pepino, pimentão e tomate, obtidos de supermercados ou do campus da UFRPE, foram lavados com sabão e água corrente, desinfestados em hipoclorito de sódio a $0,5 \%$, por $10 \mathrm{mi}$ nutos, lavados por duas vezes com água destilada esterilizada e secos à temperatura ambiente. Estes frutos foram inoculados pelo método de injeção subepidérmica (Somodi et al., 1991) que consistiu na introdução de $100 \mu \mathrm{l}$ de suspensão bacteriana dos isolados Aac 1.49 e Aac 12.13, na concentração 3,4 x $10^{7} \mathrm{UFC} \mathrm{ml}^{-1}$, logo abaixo da superfície da casca, com auxílio de uma seringa hipodérmica. Nos frutos de maior tamanho (abóbora, melancia e melão) foram marcadas quatro seções perpendiculares ao seu comprimento e em cada seção foram injetados três pontos. Nos frutos de menor tamanho (abobrinha, berinjela, mamão, maxixe, pepino, pimentão, e tomate) foram marcados três pontos ao longo do comprimento. Os frutos foram mantidos individualmente em câmara úmida por $48 \mathrm{~h}$ e incubados em casa de vegetação. A incidência da doença e o período de incubação foram avaliados diariamente a partir das $24 \mathrm{~h}$ após a inoculação. A severidade foi avaliada após o período de incubação que variou conforme o hospedeiro, medindo-se o diâmetro da lesão externa (DLE) e 


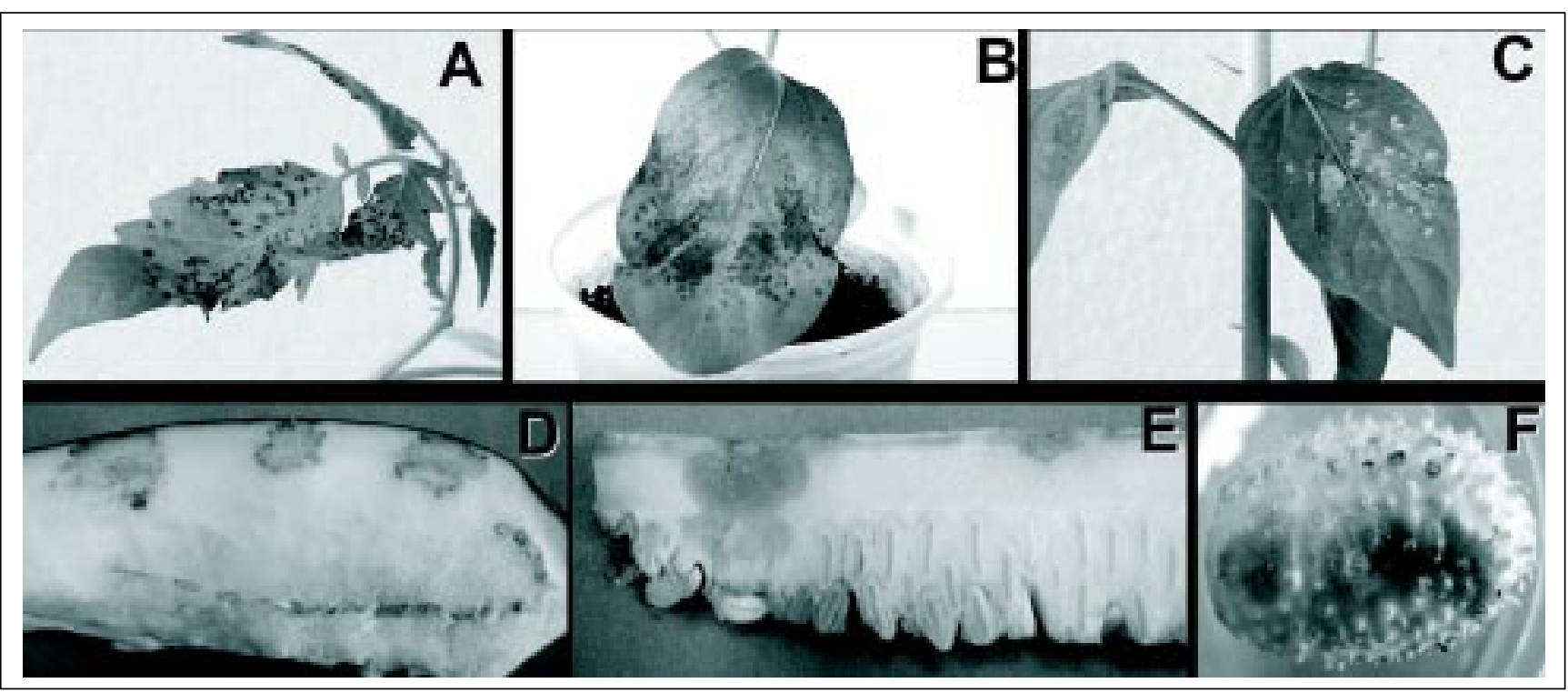

Figura 1. Sintomas em hospedeiros alternativos de Acidovorax avenae subsp. citrulli: A) tomate, B) berinjela, C) pimentão, D) berinjela fruto, E) pepino fruto e F) maxixe fruto. Recife, UFRPE, 2002.

profundidade da lesão (PL), com auxílio de uma régua milimetrada.

Durante o período de realização dos experimentos, a temperatura média na casa de vegetação foi de $30 \pm 3^{\circ} \mathrm{C}$, e a UR média foi de $81 \pm 2,5 \%$.

$\mathrm{O}$ delineamento experimental foi inteiramente casualizado, em arranjo fatorial $2 \times 10$, representados por dois isolados de Aac e frutos de dez espécies botânicas diferentes, com quatro repetições. A unidade experimental foi constituída por três pontos de inoculação.

Os dados obtidos foram submetidos à análise de variância, e as médias foram comparadas pelo teste de Tukey a $1 \%$ de probabilidade com auxílio do programa SANEST (Sistema de Análises Estatísticas, Instituto Agronômico de Campinas, 1989).

\section{RESULTADOS E DISCUSSÃO}

Na avaliação da reação de espécies/ cultivares à Aac, houve diferenças significativas com relação ao PI apenas entre espécies (Tabela 1). Já com relação a INC foram detectadas diferenças entre espécies, e para a interação espécies $\mathrm{x}$ isolados. O'Brien e Martin (1999) observaram interação significativa entre isolados de Aac x cultivares de melancia e melão, com relação à severidade da doença em plântulas.

Tabela 1. Patogenicidade de isolados de Acidovorax avenae subsp. citrulli (Aac 1.49 e 12.13) a plantas de diferentes espécies/cultivares, avaliadas por um período de até 10 dias, em condições de casa de vegetação. Recife, UFRPE, 2002.

\begin{tabular}{lccc}
\hline \multirow{2}{*}{ Hospedeiros } & $\begin{array}{c}\text { Período de } \\
\text { incubação (d) }\end{array}$ & \multicolumn{2}{c}{ Incidência (\%) ${ }^{\mathbf{2}}$} \\
\cline { 3 - 4 } & $3,00^{3} \mathrm{c}$ & $100,00 \mathrm{a}$ & $100,00 \mathrm{a}$ \\
Abóbora 'Menina creme' & $3,00 \mathrm{c}$ & $100,00 \mathrm{a}$ & $100,00 \mathrm{a}$ \\
Abobrinha 'Morena brasileira' & $3,00 \mathrm{c}$ & $100,00 \mathrm{a}$ & $100,00 \mathrm{a}$ \\
Cabaça & $3,00 \mathrm{c}$ & $100,00 \mathrm{a}$ & $100,00 \mathrm{a}$ \\
Maxixe 'do Norte' & $3,00 \mathrm{c}$ & $100,00 \mathrm{a}$ & $100,00 \mathrm{a}$ \\
Melancia4 'Charleston Gray' & $3,00 \mathrm{c}$ & $100,00 \mathrm{a}$ & $100,00 \mathrm{a}$ \\
Melão4 'Pele de Sapo' & $3,00 \mathrm{c}$ & $100,00 \mathrm{a}$ & $100,00 \mathrm{a}$ \\
Melão-pepino & $3,00 \mathrm{c}$ & $100,00 \mathrm{a}$ & $100,00 \mathrm{a}$ \\
Melão de São Caetano & $3,00 \mathrm{c}$ & $100,00 \mathrm{a}$ & $100,00 \mathrm{a}$ \\
Moranga 'Exposição' & $3,00 \mathrm{c}$ & $100,00 \mathrm{a}$ & $100,00 \mathrm{a}$ \\
Pepino 'SMR 58' & $3,50 \mathrm{c}$ & $100,00 \mathrm{a}$ & $100,00 \mathrm{a}$ \\
Berinjela 'Comprida roxa' & $3,17 \mathrm{c}$ & $100,00 \mathrm{a}$ & $100,00 \mathrm{a}$ \\
Tomate 'Santa Clara' & $3,33 \mathrm{c}$ & $91,60 \mathrm{a}$ & $100,00 \mathrm{a}$ \\
Pimentão 'All big' & $5,17 \mathrm{bc}$ & $33,33 \mathrm{~b}$ & $58,33 \mathrm{~b}$ \\
Mamão 'Sunrise solo' & $6,83 \mathrm{~b}$ & $33,33 \mathrm{~b}$ & $66,67 \mathrm{~b}$ \\
Bucha & $11,00 \mathrm{a}$ & $0,0 \mathrm{c}$ & $0,0 \mathrm{c}$ \\
Caupi & $11,00 \mathrm{a}$ & $0,0 \mathrm{c}$ & $0,0 \mathrm{c}$ \\
Feijão 'Princesa' & $11,00 \mathrm{a}$ & $0,0 \mathrm{c}$ & $0,0 \mathrm{c}$ \\
Fumo & $11,00 \mathrm{a}$ & $0,0 \mathrm{c}$ & $0,0 \mathrm{c}$ \\
Milho 'São José' & 22,64 & 8,65 & \\
\hline C.V. (\%) & & &
\end{tabular}

${ }^{1}$ Determinado pelo número de dias entre a inoculação e o surgimento de sintomas da mancha-aquosa. Plantas que não apresentaram sintomas tiveram PI ajustado para o período de avaliação total acrescido de mais um dia (Iamsupasit et al., 1993).

${ }^{2}$ Calculada pela percentagem de plantas inoculadas que apresentaram sintomas da doença. ${ }^{3}$ Médias de seis repetições. Médias seguidas da mesma letra na vertical não diferem significamente entre si pelo teste de Tukey, a $1 \%$ de probabilidade.

${ }^{4}$ Utilizados como padrões de suscetibilidade.

Ambos os isolados causaram rápidos sintomas de mancha-aquosa, indi- cando alta agressividade, o que também foi verificado por Silveira et al. (2003), 
Tabela 2. Período de incubação (PI), incidência (INC) da mancha aquosa, diâmetro da lesão externa (DLE) e profundidade da lesão (PL) em frutos de diferentes hospedeiros, causadas por isolados de Acidovorax avenae subsp. citrulli (Aac 1.49 e 12.13). Recife, UFRPE, 2002.

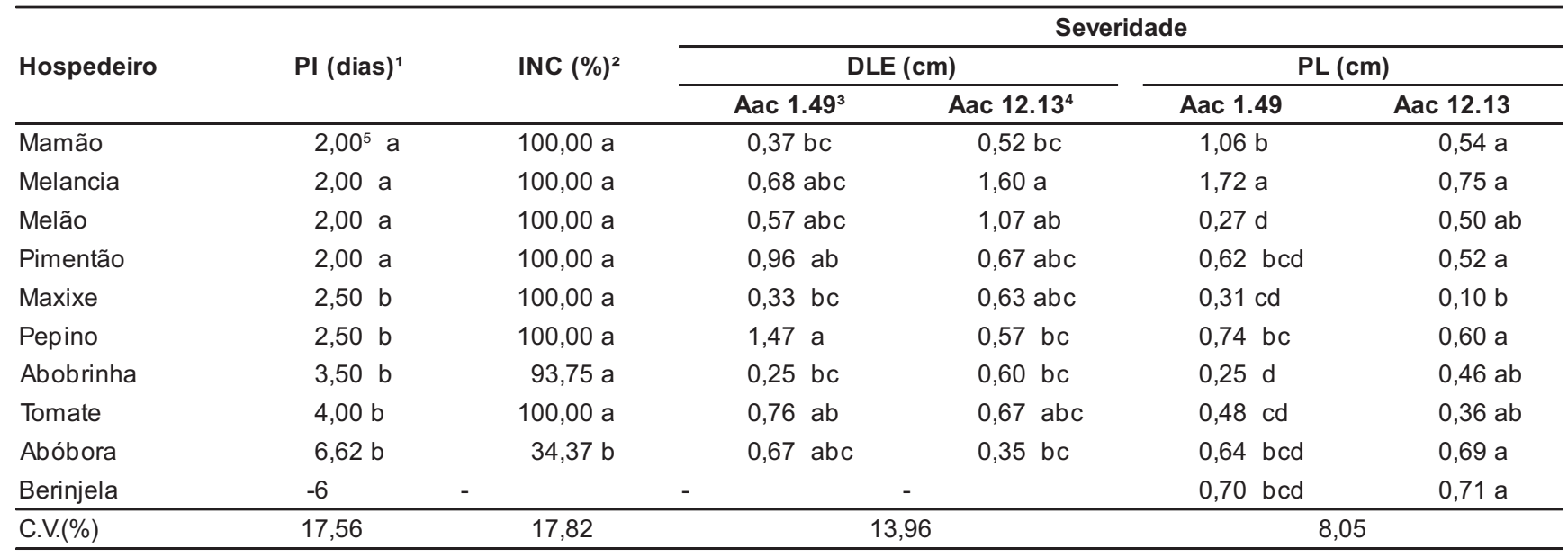

${ }^{1}$ Determinado pelo número de dias entre a inoculação e o surgimento de sintomas nos frutos.

${ }^{2}$ Calculada pelo número de frutos inoculados que apresentaram sintomas.

${ }^{3}$ Isolado de Aac obtido de melão.

${ }^{4}$ Isolado de Aac obtido de melancia.

${ }^{5}$ Média de quatro repetições. Médias seguidas pela mesma letra na vertical não diferem significativamente entre si, pelo teste Tukey, a $1 \%$ de probabilidade. Dados de PI, DLE e PL transformados em $\mathbf{V x}+0,5$.

${ }^{6}$ Nos frutos de berinjela, devido à coloração escura, não se pode observar as lesões externas.

em plântulas e frutos de melão, inoculados com diferentes isolados de Aac (Figura 1).

Todas as solanáceas e cucurbitáceas, exceto a bucha, apresentaram PI em torno de três dias, não diferindo entre si. A bucha (6,83 dias) diferiu significativamente do primeiro grupo, mas não diferiu do mamão (5,17 dias) (Tabela 1). Rane e Latin (1992) verificaram PI de 2 dias em plântulas de melancia com 1012 dias. Já Silveira et al. (2003) inoculando sementes de melão, observaram sintomas em plântulas após 4,1 dias.

A incidência da mancha-aquosa nas plântulas suscetíveis foi máxima (100\%) nas cucurbitáceas, exceto a bucha $(33,33$ e $66,67 \%$ ), respectivamente para os isolados Aac 1.42 e Aac 12.13 e nas solanáceas com exceção do pimentão $(91,6 \%)$ para Aac 1.42 (Tabela 1). Para ambos os isolados de Aac, as cucurbitáceas e solanáceas diferiram significativamente da bucha e do mamão, que não diferiram entre si. Não houve incidência de mancha-aquosa em caupi, feijão, fumo e milho. Dentre as cucurbitáceas testadas, todas se mostraram suscetíveis ao patógeno, confirmando o que já havia sido citado na literatura para melão (Isakeit et al, 1997), melancia (Assouline, 1997) e melão-pepino (Oliveira et al., 2003). A bucha e o melão de
São Caetano, cujo papel na sobrevivência da bactéria foi sugerido por Viana $e t$ al. (2000), tiveram suscetibilidade confirmada neste trabalho, devendo, assim, serem erradicadas das áreas de plantio, juntamente com o maxixe. O melão Pele de sapo também se comportou como suscetível, concordando com Silva et al. (2003) que relataram incidências de 46,63 e 47,29\%, respectivamente, em duas áreas de Mossoró (RN). As solanáceas, tomate, berinjela e pimentão foram suscetíveis a Aac, conforme relatado por Assouline et al. (1997). O'Brien (2002) também observou que essas plantas foram infectadas pelo patógeno em condições de casa de vegetação. Este autor relacionou a sobrevivência de Aac com cucurbitáceas selvagens, como Cucumis myriocarpus Naudin subsp. myriocarpus, nos arredores dos plantios de melancia.

O milho e outras gramíneas como o sorgo são utilizados na rotação de culturas com o melão nos estados do RN (Silva et al., 2003) e CE. Nas condições avaliadas, o milho não foi suscetível ao patógeno, recomendando-se a continuidade de seu uso pelos produtores. $\mathrm{Na}$ região do Submédio São Francisco, em Petrolina (PE) e Juazeiro (BA), cultivase o melão em rotação com cebola, tomate, pimentão, feijão e milho (comu- nicação pessoal, Dra. Rita de Cássia S. Dias, Embrapa Semi-Árido). Assim devem ser evitados os plantios de tomate e pimentão, pois se mostraram suscetíveis Aac, já o feijão e o milho podem ser mantidos. Também com base nos resultados obtidos, recomenda-se evitar o plantio de abóbora, abobrinha, berinjela, melancia, melão-pepino e o pepino próximo a plantios de melão.

Os sintomas obtidos, tanto nas folhas quanto nos frutos dos diferentes hospedeiros avaliados (Figura 1), foram semelhantes àqueles observados em melão.

$\mathrm{Na}$ avaliação da reação de frutos a Aac utilizando o PI e a INC, houve diferença significativa apenas entre hospedeiros (Tabela 2). No entanto, quando se avaliou a severidade através da DLE e PL, houve diferença significativa para todos os fatores e interações, exceto para isolados na DLE.

Em frutos, o PI variou de 2,0 dias para mamão, melancia, melão e pimentão até 6,62 dias para abóbora (Tabela 2). Somodi et al. (1991), na Flórida, obtiveram sintomas da doença em frutos de melancia dois dias após a inoculação. No Brasil, PIs de 2,2 e 2,4 dias foram obtidos para melão, respectivamente por Silveira et al. (2003) e Araújo (2002). 
A incidência em frutos variou de $34,37 \%$ em abóbora a $100 \%$ em mamão, maxixe, melancia, melão, pepino, pimentão e tomate (Tabela 2). Frutos maduros dos hospedeiros testados não ofereceram barreiras à colonização por $A$. avenae subsp. citrulli quando inoculados com suspensão do patógeno por injeção subepidérmica. Resultados semelhantes foram obtidos por Araújo (2002) ao inocular frutos de melão tipo Amarelo por este mesmo método, obtendo maior incidência da doença em comparação a outros métodos de inoculação avaliados (deposição de gota e pulverização, ambos com e sem ferimentos). O método de inoculação por injeção subepidérmica foi utilizado por Somodi et al. (1991) e Isakeit et al (1997) em frutos de melancia e melão, respectivamente, com bons resultados.

Para o isolado Aac 1.49 (proveniente de melão) (Tabela 2), a DLE variou de $1,47 \mathrm{~cm}$ em pepino a $0,25 \mathrm{~cm}$ em abobrinha, e para Aac 12.13 (proveniente de melancia) variou de $1,60 \mathrm{~cm}$ em melancia a $0,35 \mathrm{~cm}$ em abobrinha. As maiores PL foram observadas em melancia $(1,72 \mathrm{~cm}$ - Aac 1.49 e $0,75 \mathrm{~cm}$ Aac 12.13) e a menor em abóbora $(0,25$ $\mathrm{cm}$ - Aac 1.49$)$ e maxixe $(0,10 \mathrm{~cm}$ - Aac 12.13). Somodi et al. (1991) verificaram que frutos de melancia inoculados com isolados de Aac, pelo mesmo método utilizado neste trabalho, apresentaram lesões de até 9,4 cm de diâmetro, 14 dias após a inoculação. Silveira et al. (2003) observaram, em frutos de melão oito dias após a inoculação com isolados de Aac, lesões médias com 1,35 cm de diâmetro e profundidade de $0,97 \mathrm{~cm}$. Estes resultados concordam também com os de Santos e Viana (2000) ao observarem que mesmo sendo pequena a lesão externa, em frutos de melão, o interior do tecido pode estar em grande parte infectado, inviabilizando estes frutos para comercialização e exportação.

É evidente a importância do estudo dos hospedeiros alternativos de $A$. avenae subsp. citrulli, pois a sobrevivência do patógeno na entressafra pode estar relacionada a cucurbitáceas selvagens e espécies de outras famílias botânicas. Este conhecimento evitará rotações de culturas ineficientes e enfatizará o cuidado com a eliminação de plantas invasoras e/ou voluntárias.

\section{LITERATURA CITADA}

ARAÚJO, D.V. Métodos de inoculação e preservação de Acidovorax avenae subsp. citrulli e sobrevivência em sementes de melão. (Tese mestrado), UFRPE, Recife, 2002. 61 p.

ASSIS, S.M.P.; MARIANO, R.L.R.; SILVAHANLIN, D.M.W.; DUARTE, V. Mancha-aquosa do melão causada por Acidovorax avenae subsp. citrulli, no estado do Rio Grande do Norte. Fitopatologia Brasileira, Brasília, v.24, n.2, p.191, 1999.

ASSOULINE, I.; MILSHTEIN, H.; MIZRAHI, M.; LEVY, E.; BEM-ZEV, I.S. Acidovorax avenae subsp. citrulli transmitted by solanaceous seeds. Phytoparasitica, v.25, p.2, 1997.

IAMSUPASIT, N.; CHAKRABORTY, S.; CAMERON, D.F.; ADKINS, S.W. Components of quantitative resistance to anthracnose (Colletotrichum gloesporioides) in tetraploid accessions of the pasture legume Stylosanthes hamata. Australian Journal of Experimental Agriculture, v.33, p.855-860, 1993.

INSTITUTO BRASILEIRO DE GEOGRAFIAE ESTATÍSTICA - IBGE. Banco de dados agregados. Brasília: Sistema IBGE de Recuperação Automática - SIDRA, 2001. Disponível em: <http:// www.sidra.ibge.gov.br/bda/tabela/protabl.asp>. Acesso em: 14 abr. 2002.

ISAKEIT, T.; BLACK, M.C.; BARMES, L.W.; JONES, J.B. First report of infection of honeydew with Acidovorax avenae subsp. citrulli. Plant Disease, v.81, n.6, p.694, 1997.

LANGSTON JR., D. B.; WALCOTT, R. D.; GITAITS, R. D.; SANDERS, F. H. First report of a fruit rot of pumpkin caused by Acidovorax avenae subsp. citrulli in Georgia. Plant Disease, v. 83, p. 199, 1999.

MACAGNAN, D.; ROMEIRO, R.S.; MENDONÇA, H.L.; BARRETO, R.W. Mancha-bacteriana da melancia: uma nova bacteriose no estado de Minas Gerais. Summa phytopatholozica, Botucatu, v. 27, n. 3, p. 286-287, 2003.

MARIANO, R.L.R.; SILVEIRA, E.B.; ASIS, S.M.P.; GOMES, A.M.A.; OLIVEIRA, I.S.; NASCIMENTO, A.R.P. Diagnose e manejo de fitobacterioses de importância no nordeste brasileiro. In: MICHEREFF, S.J.; BARROS, R. (Eds.) Proteção de plantas na agricultura sustentável. Recife: UFRPE, Imprensa Universitária, 2001. 368 p.
O'BRIEN, R.G. Bacterial fruit blotch of melons. HO144, August 2000. Disponível em: <www.dpi.qi>. Acesso em: 11 jun 2002.

O'BRIEN, R.G.; MARTIN, A.L. Bacterial blotch of melons caused by strains of Acidovorax avenae subsp. citrulli. Australian Journal of Experimental Agriculture, v.39, p.479-485, 1999.

OLIVEIRA, I.S.; SALES JÚNIOR, R.; MARIANO, R.L.R.; Ocorrência da mancha-aquosa causada por Acidovorax avenae subsp. citrulli, em melão-pepino no Brasil. Fitopatologia Brasileira, Brasília, v.28 n.6, p.686, 2003.

RANE, K.K.; LATIN, R.X. Bacterial fruit blotch of watermelon: Association of the pathogen with seed. Plant Disease, v.76, n.2, p.509-512, 1992. ROBBS, C.F.; RODRIGUES NETO, J.; BERIAN, L.O.S. Podridões de frutos de melão em pós-colheita causadas por bactérias no Brasil. Fitopatologia Brasileira, Brasília, v.17, n.2, p.195, 1992.

ROBBS, C.F.; RODRIGUES NETO, J.; RAMOS, R.S.; SINIGAGLIA, C. Mancha bacteriana da melancia no estado de São Paulo, causada por Pseudomonas pseudoalcaligenes subsp. citrulli. Fitopatologia Brasileira, Brasília, v.16, n.2, p.XLVIII, 1991.

SANTOS, A.A.; VIANA, F.M. Mancha-aquosa do melão. Fortaleza: EMBRAPA. 2000. 2p.

SILVA, E.I.; MARIANO, R.L.R.; MICHEREFF, S.J.; SALES JÚNIOR, R.; OLIVEIRA, I.S. Levantamento da incidência da mancha-aquosa do melão no Rio Grande do Norte e determinação do tamanho da amostra para quantificação da doença. Summa Phytopathologica, Botucatu, v.29, n.2, p.173-176, 2003.

SILVEIRA, E.B.; MARIANO, R.L.R.; MICHEREFF, S.J. Variabilidade de isolados de Acidovorax avenae subsp. citrulli provenientes de melão produzido no estado do Rio Grande do Norte. Summa Phytopathologica, Botucatu, v.29, n.3, p.255-261, 2003.

SOMODI, G.C.; JONES, J.B.; HOPKINS, D.L.; STALL, R.E.; KUCHAREK, T.A.; HODGE, N.C.; WATTERSON, J.C. Occurrence of a bacterial watermelon fruit blotch in Florida. Plant Disease, v.75, n.10, p.1053-1056, 1991.

UENO, B.; COUTO MELO, M.E.O.; UESUGI, C.H. Ocorrência de mancha-aquosa em melão no estado do Rio Grande do Sul. Fitopatologia Brasileira, Brasília, v.28, Suplemento, p.246. 2003.

VIANA, F.M.P.; SANTOS, A.A.; CARDOSO, J.E.; FREIRE, F.C.O.; LOPES, C.A. Surto da mancha-aquosa em frutos de melão nos Estados do Ceará e Rio Grande do Norte: recomendações preliminares de controle. Fortaleza: EMBRAPA Agroindústria Tropical, 2000. (Comunicado Técnico, 50)

WEBB, R.E.; GOTH, R.W. A seedborne bacterium isolated from watermelon. Plant Disease Reporter, Beltsville, v.48, p.818-821, 1965. 